Website:http://ejournal.uncen.ac.id/index.php/JIPI

\title{
Kecerdasan Spiritual Dikembangkan Melalui Metode Bercerita Pada Anak
}

Andrianus Krobo - krobozon@ gmail.com

Fakultas Keguruan dan Ilmu Pendidikan Universitas Cenerawasih

\begin{abstract}
The purpose of this study was to determine the development of spiritual intelligence through a method of telling stories to children in group B1 of YPPK TK Christ Terang Dunia. The results of the study showed that the spiritual intelligence of group BI children in YPPK TK Christ Terang Dunia can be developed through storytelling methods.
\end{abstract}

Keywords: Spiritual Intelligence, Storytelling Method.

\section{ABSTRAK}

Tujuan dari penelitian ini adalah untuk mengetahui perkembangan kecerdasan spiritual melalui metode bercerita pada anak kelompok B1 TK YPPK Kristus Terang Dunia. Hasil penelitian menunjukkan bahwa kecerdasan spiritual anak kelompok B1 TK YPPK Kristus Terang Dunia dapat dikembangkan melalui metode bercerita.

Kata kunci: Kecerdasan Spiritual, Metode Bercerita.

\section{PENDAHULUAN}

Pendidikan anak usia dini pada dasarnya meliputi seluruh upaya dan tindakan yang dilakukan oleh pendidik dan orang tua dalam proses perawatan, pengasuhan dan pendidikan pada anak dengan menciptakanaura dan lingkungan dimana anak dapat mengeksplorasi pengalaman yang memberikan kesempatan kepadanya untuk mengetahui dan memahami pengalaman belajar yang diperolehnya dari lingkungan, melalui cara mengamati, meniru dan bereksperimen yang berlangsung secara berulang-ulang dan melibatkan seluruh potensi dan kecerdasan anak, (Sujiono 2013:7)
Howard Gardner (Dalam Suparno, 2004:17) mendifinisikan kecerdasan sebagai "Kemampuan untuk memecahkan persoalan dan menghasilkan produk dalam suatu seting yang bermacam-macam dan dalam situasi yang nyata”. Kecerdasan bukan hanya kemampuan seseorang untuk menjawab suatu tes IQ dalam kamar tertutup yang lepas dari lingkungannya, tetapi kecerdasan memuat kemampuan untuk memecahkan persoalan yang nyata dalam suatu situasi yang bermacammacam. Pratisti (2008: 56) menyatakan bahwa usia dini pada anak kadangkadang disebut sebagai usia emas atau 
golden age. Masa-masa tersebut merupakan masa kritis dimana seorang anak membutuhkan rangsanganrangsangan yang tepat untuk mencapai kematangan yang sempurna.Yang kami maksud sebagai masa kritis adalah saat yang sangat mempengaruhi keberhasilan pada masa berikutnya. Apabila masa kritis ini tidak memperoleh rangsangan yang tepat dalam bentuk latihan atau proses belajar maka diperkirakan anak akan mengalami kesulitan pada masa-masa perkembangan berikutnya.

Anak belajar sesuatu dengan melihat gambaran besar berupa perilaku terbaik atau akhlak orang-orang terdekat dan lingkungan sekitarnya. Sejak balita hingga beranjak dewasa, anak merekam, memperkaya pengetahuan dan keterampilan hidupnya, sama seperti ketika anak menonton televisi. Jika lingkungan memberikan stimulus yang tepat maka anak akan memahami, mengerti dan cerdas. Sebaliknya, jika stimulus yang diberikan tidak tepat, maka anak akan sulit memahami apa yang diajarkan.

Menurut Chatib (2014: 100) lingkungan menjadi katalis bagi anak agar berperilaku baik dan penghambat bagi anak yang berperilaku kasar. Lingkungan positif mempercepat anak menemukan simpul-simpul eksistensinya terhadap makna kehidupan. Sementara, lingkungan negatif menjadi penghambat bagi anak dalam menemukan simpul kebaikan perilakunya. Pendidikan anak usia dini mengajarkan akhlak dan moral kebaikan serta agama dan nilai-nilai kehidupan sehingga mendorong anak bertanya "untuk apa kita hidup?”, “untuk apa kita beribadah?", atau "untuk apa kita berbuat kebaikan terhadap sesama?"

Kecerdasan spiritual memiliki peran yang penting bagi setiap anak karena berkaitan dengan praktek hidup sesuai dengan norma agama dan moral. Kesanggupan anak membedakan mana yang baik dan benar, yang berkenan kepada Tuhan merupakan kunci pembentukan hati nurani anak. Hati nurani merupakan elemen inti dalam diri setiap manusia yang berfungsi untuk selalu mengarahkan seseorang kepada kebenaran dan kebaikan dan sebaliknya menghindari kesalahan dan keburukan.

Berdasarkan hasil pengamatan dan hasil evaluasi terhadap anak-anak kelompok B1 di TK YPPK Kristus Terang Dunia Kota Jayapura, ditemukan kesenjangan antara kenyataan dan tujuan sekolah yaitu menciptakan generasi yang cinta damai, peduli sesama dan lingkungan serta cerdas dalam Terang Injil. Sejumlah 
gejala seperti bermain saat berdoa, mengolok-olok teman, memakai katakata yang tidak sopan, membuang sampah sembarangan, bercerita sendiri saat guru menjelaskan, tidak memotong kuku sehingga terlihat kotor dan tajam, tidak menjaga kebersihan tubuhnya, dan lain-lain merupakan indikasi perlunya pengembangan dan peningkatan kecerdasan spiritual pada anak.

\section{METODE PENELITIAN}

Penelitian ini dilaksanakan di Taman Kanak-kanak Kristus Terang Dunia, yang beralamat di Waena Perumnas 2 Jln. Proyek. Kota Jayapura Provinsi Papua.Waktu pelaksanaan penelitian selama semester ganjil tahun ajaran 2016/2017. Penelitian ini menggunakan metode penelitian tindakan (action research). Kemiss dalam Komaidi dan Wijayati (2011) bahwa: Action research as a reflective inquiry undertaken by participants in a social (including edicational) situation in order to improve the rationality and justice of (a) their on social or educational practices, (b) their understanding of these practices, and (c) the situations in which practices are carried out.

Instrumen yang digunakan yaitu peningkatan kecerdasan spiritual adalah skor yang diperoleh melalui tes kecerdasan spiritual yang berbentuk pengamatan (observasi) menggunakan skala rating scale selama pelaksanaan tindakan.Uji validitas instrumen ini dilakukan dengan meminta pertimbangan dari tenaga ahli sesuai dengan judul penelitian atau materi konten yang ada dalam penelitian ini. Analisis data dilakuakan dengan menggunakan mixed methods research is a research design with philosophical assumption as well as methods of inquiry. as a methodology, it involves philosophical assumptions that guide the direction of the collection and analysis of data and the mixture of qualitative and quantitative approaches in many phases in the research process (Creswell \& Clark, 2007:5). Kompilasi data antara kualitatif dan kuantitatif, yaitu analisis dan refleksi dalam siklus berdasarkan hasil observasi yang terekam dalam catatan lapangan dan format pengamatan lainnya, reduksi data, penyajian data dan penarikan kesimpulan.

\section{HASIL DAN PEMBAHASAN}

Data awal tentang sikap Spiritual Rasa Syukur Pada Tuhan pada anak kelompok B1 TK YPPK Kristus Terang Dunia ditunjukan pada Tabel 1. 
Tabel 1 Sikap Rasa Syukur Pada Tuhan

\begin{tabular}{|c|c|c|c|c|c|}
\hline \multirow[b]{2}{*}{ No } & \multirow[b]{2}{*}{ Nama } & \multicolumn{3}{|c|}{ Aspek-Aspek Yang Dinilai } & \multirow[b]{2}{*}{ Prosentase } \\
\hline & & $\begin{array}{c}\text { Menghargai } \\
\text { diri sendiri }\end{array}$ & $\begin{array}{c}\text { Menghargai } \\
\text { orang lain }\end{array}$ & $\begin{array}{c}\text { Menghargai } \\
\text { lingkungan } \\
\text { sekitar }\end{array}$ & \\
\hline 1 & $\mathrm{AG}$ & $* * * *$ & $* * * *$ & $* * * *$ & $100 \%$ \\
\hline 2 & JP & $* * * *$ & $* * * *$ & $* * * *$ & $100 \%$ \\
\hline 3 & $\mathrm{DN}$ & $* * * *$ & $* * * *$ & $* * * *$ & $100 \%$ \\
\hline 4 & $\mathrm{DM}$ & $* * *$ & $* * * *$ & $* * * *$ & $92 \%$ \\
\hline 5 & AK & $* * * *$ & $* * * *$ & $* * *$ & $92 \%$ \\
\hline 6 & $\mathrm{IM}$ & $* * * *$ & $* * *$ & $* * * *$ & $92 \%$ \\
\hline 7 & GL & $* * * *$ & $* * *$ & $* * *$ & $83 \%$ \\
\hline 8 & PT & $* * * *$ & $* * *$ & $* * *$ & $83 \%$ \\
\hline 9 & IA & $* * *$ & $* * *$ & $* * *$ & $75 \%$ \\
\hline 10 & VM & $* *$ & $* * *$ & $* *$ & $58 \%$ \\
\hline 11 & YS & $* * *$ & $* *$ & $* *$ & $58 \%$ \\
\hline 12 & $\mathrm{JM}$ & $* *$ & $* *$ & $* *$ & $50 \%$ \\
\hline 13 & CL & $* *$ & $* *$ & $* *$ & $50 \%$ \\
\hline 14 & MS & $* *$ & $* *$ & $* *$ & $50 \%$ \\
\hline 15 & DB & $* * *$ & $* *$ & $*$ & $50 \%$ \\
\hline 16 & $\mathrm{KP}$ & $* *$ & $* *$ & $* *$ & $50 \%$ \\
\hline 17 & JK & $* *$ & $*$ & $* *$ & $42 \%$ \\
\hline 18 & JD & $* *$ & $* *$ & $*$ & $42 \%$ \\
\hline 19 & $\mathrm{AF}$ & $* *$ & $* *$ & $*$ & $42 \%$ \\
\hline 20 & MY & $* *$ & $*$ & $*$ & $33 \%$ \\
\hline 21 & $\mathrm{BL}$ & $* *$ & * & $*$ & $33 \%$ \\
\hline 22 & $\mathrm{AK}$ & $*$ & $*$ & $*$ & $25 \%$ \\
\hline \multicolumn{2}{|c|}{ Rata-Rata } & 69,31 & 60,23 & 59,09 & $57,14 \%$ \\
\hline
\end{tabular}

Sumber data : Data primer diolah tahun 2017

(BSB menyatakan

Berkembang Sangat Baik = ****), (BSH menyatakan Berkembang Sesuai Harapan =
***), (MB menyatakan Mulai Berkembang $=* *$ ) dan $\mathrm{BB}$ menyatakan Belum Berkembang $=*)$ 
Berdasarkan $\quad$ Tabel 1

menunjukkan bahwa Peningkatan

Kecerdasan spiritual terjadi melalui kegiatan bercerita di kelompok B1 Taman Kanak-kanak Kristus Terang Dunia Waena Perumnas II Kota Jayapura. Hal ini dibuktikan dengan kecerdasan spiritual awal mencapai $57,14 \%$ meliputi aspek menghargai diri sendiri mencapai 69,31\%, menghargai orang lain mencapai 60,23\%, menghargai lingkungan hidup 59,09.

Hal ini disebabkan prosedur/langkah-langkah dan teknik bercerita sejak awal hinga akhir seperti;memotivasi anak-anak, menetapkan tujuan dan tema cerita, menetapkan bentuk bercerita yang dipilih, menetapkan bahan dan alat yang diperlukan dalam kegiatan bercerita, menetapkan rancangan langkah-langkah /mengurutkan kegiatan bercerita seperti : (mengkomunikasikan tujuan dan tema cerita, mengatur tempat duduk anak, kegiatan pembukaan bercerita, pengembangan cerita, menetapkan teknik bertutur yang akan digunakan sehingga cerita yang disampaikan dapat tepat sasaran, merupakan langkah penutup kegiatan bercerita dengan mengajukan pertanyaan-pertanyaan yang berkaitan dengan isi cerita), menetapkan rancangan penilaian kegiatan bercerita.
Mengembangkan situasi permasalahan cerita dengan pengalaman nyata dan cerita yang tengah berlangsung, mengeksplorasi prinsip umum tentang perilaku di lalui dengan baik, sehingga anak-anak termotivasi dan apresisasi terhadap semua cerita-cerita yang di ceritakan guru serta anak anak tidak segan-segan untuk mengomentari /bertanya, yang di ceritakan oleh guru, bahkan kadang terjadi interupsiinterupsi atau pro dan kontra opini dikalangan anak-anak untuk membenarkan dan meneruskan/menyambung gagasan pengembangan cerita menurut intelektual daya imajinasi anak-anak tersebut terjadi dalam hal verbal maupun nonverbal yang dilakukan oleh anak anak, Hal inilah yang menjadi indicator meningkatnya kecerdasan spiritual anak

Kelengkapan media bantu cerita perlu ditambah, seting ruang kelas sesuai dengan cerita perlu lebih diperhatikan, pada sat cerita perlu ulasan-ulasan dan penegasan-penegasan dari guru pada nilai-nilai spiritualitas yang hendak di patrikan pada jiwa dan perilaku anak-anak Taman KanakKanak Kristus Terang Dunia Waena Perumnas II ditunjukan pada Tabel 2. 
Tabel 2 Kecerdasan Spiritual Anak

\begin{tabular}{|c|c|c|c|c|c|}
\hline \multirow[b]{2}{*}{ No } & \multirow[b]{2}{*}{ Nama } & \multicolumn{3}{|c|}{ Aspek-Aspek Yang Dinilai } & \multirow[b]{2}{*}{ Presentase } \\
\hline & & $\begin{array}{l}\text { Menghargai diri } \\
\text { sendiri }\end{array}$ & $\begin{array}{l}\text { Menghargai } \\
\text { orang lain }\end{array}$ & $\begin{array}{l}\text { Menghargai } \\
\text { lingkungan } \\
\text { sekitar }\end{array}$ & \\
\hline 1 & $\mathrm{AG}$ & $* * * *$ & $* * * *$ & $* * * *$ & $100 \%$ \\
\hline 2 & JP & $* * * *$ & $* * * *$ & $* * * *$ & $100 \%$ \\
\hline 3 & $\mathrm{DN}$ & $* * * *$ & $* * * *$ & $* * * *$ & $100 \%$ \\
\hline 4 & DM & $* * * *$ & $* * * *$ & $* * * *$ & $100 \%$ \\
\hline 5 & $\mathrm{AK}$ & $* * * *$ & $* * * *$ & $* * * *$ & $100 \%$ \\
\hline 6 & $\mathrm{IM}$ & $* * * *$ & $* * * *$ & $* * * *$ & $100 \%$ \\
\hline 7 & GL & $* * * *$ & $* * * *$ & $* * * *$ & $100 \%$ \\
\hline 8 & PT & $* * * *$ & $* * * *$ & $* * * *$ & $100 \%$ \\
\hline 9 & IA & $* * * *$ & $* * * *$ & $* * *$ & $92 \%$ \\
\hline 10 & VM & $* * * *$ & $* * *$ & $* * * *$ & $92 \%$ \\
\hline 11 & YS & $* * * *$ & $* * * *$ & $* * * *$ & $100 \%$ \\
\hline 12 & JM & $* * * *$ & $* * *$ & $* * *$ & $83 \%$ \\
\hline 13 & $\mathrm{CL}$ & $* * * *$ & $* * * *$ & $* * *$ & $92 \%$ \\
\hline 14 & MS & $* * * *$ & $* * *$ & $* * *$ & $83 \%$ \\
\hline 15 & DB & $* * * *$ & $* * *$ & $* * *$ & $83 \%$ \\
\hline 16 & $\mathrm{KP}$ & $* * * *$ & $* * * *$ & $* * *$ & $92 \%$ \\
\hline 17 & $\mathrm{JK}$ & $* * * *$ & $* * *$ & $* * * *$ & $92 \%$ \\
\hline 18 & JD & $* * * *$ & $* * *$ & $* * * *$ & $92 \%$ \\
\hline 19 & $\mathrm{AF}$ & $* * * *$ & $* * *$ & $* * *$ & $83 \%$ \\
\hline 20 & MY & $* * * *$ & $* * *$ & $* * * *$ & $92 \%$ \\
\hline 21 & $\mathrm{BL}$ & $* * * *$ & $* * * *$ & $* * *$ & $92 \%$ \\
\hline 22 & $\mathrm{AK}$ & $* * *$ & $* * *$ & $* * * *$ & $83 \%$ \\
\hline \multicolumn{2}{|c|}{ Rata-Rata } & 98,86 & 87,5 & 90,90 & $92,42 \%$ \\
\hline
\end{tabular}

Sumber data : Data primer diolah tahun 2017

Berdasarkan tabel 2 mencapai 87,5\%, mengahargai menunjukkan bahwa setelah lingkungan sekitar menapai 90,90\%. pembelajaran tematik menggunakan metode bercerita hasil menunjukkan bahwa kecerdasan spiritual meningkat menjadi $92,42 \%$ meliputi aspek menghargai diri sendiri mencapai $98,86 \%$, menghargai orang lain Menurut Moeslichatoen R. (Dalam Masitoh, dkk, 2009:10.3) menyatakan bahwa: "Metode bercerita merupakan salah satu pemberian pengalaman bagi anak dengan membawakan cerita kepadaanak secara lisan”. Sedangkan 
menurut Depdikbud (1995: 11) metode berceritaadalah "Cara bertutur dan menyampaikan cerita atau memberikan penerangan secara lisan".

Gunarti (2010:5.3) menyatakan bahwa bercerita adalah "Suatu kegiatan yang dilakukan seseorang untuk menyampaikan suatu pesan, informasi atau sebuah dongeng belaka, yang bisa dilakukan secara lisan atau tertulis". Sedangkan menurut Departemen Pendidikan Nasional (2003: 18) metode bercerita adalah "Cara bertutur kata dan menyampaikan cerita atau Menanamkan pesan-pesan atau nilai-nilai sosial, moral dan agama yang terkandung dalam sebuah cerita, sehingga anak dapat menghayatinya dan menjalankannya dalam kehidupan sehari-hari.

Berdasarkan uraian tersebut, dapat ditegaskan bahwa tujuan bercerita padaanak adalah membantu pembentukan pribadi, moral dan agama anak, mengembangkan bahasa, serta memperluas wawasan dan cara berpikir anak. Tujuan bercerita yang diharapkan pada anak Kelompok B1 TK YPPK Kristus Terang Dunia adalah dapat mengembangkan sikap spiritual "Rasa syukur pada Tuhan" sehingga anak dapat menghargai diri sendiri, orang lain dan lingkungan sekitar.
Untuk dapat menjadi seorang pencerita yang baik, hendaknya guru memperhatikan beberapa teknik dalam bercerita. Menurut Masitoh (2009:10.5) teknik yang bisa digunakan dalam bercerita adalah "Membaca langsung dari buku cerita, bercerita dengan menggunakan ilustrasi gambar dari buku, menceritakan dongeng, bercerita dengan menggunakan papan flanel, bercerita dengan menggunakan media boneka, dramatisasi suatu cerita dan bercerita sambil memainkan jari-jari tangan". Ada tujuh teknik bercerita dimaksud adalah:

1. Membaca langsung dari buku cerita. Membaca langsung dari buku cerita dapat dilakukan jika guru memiliki buku cerita yang sesuai dengan anak, terutama dikaitkan dengan pesan-pesan yang tersirat di dalam cerita tersebut. Teknik bercerita dengan membacakan langsung perlu memperhatikan pula teknik membaca, agar cerita yang dibawakan menjadi menarik serta "berjiwa" karena guru membacakannya dengan intonasi suara, lafal dan ekspresi wajah yang tepat.

2. Bercerita dengan menggunakan ilustrasi gambar dari buku.

Bila cerita yang disampaikan pada anak terlalu panjang dan terinci 
dengan menambahkan ilustrasi gambar dari buku yang dapat menarik perhatian anak, maka teknik bercerita ini akan berfungsi dengan baik. Penggunaan ilustrasi gambar dalam bercerita dimaksudkan untuk memperjelas pesan-pesan yang dituturkan, juga untuk mengikat perhatian anak pada jalannya cerita. Hal ini juga untuk memberikan variasi dalam aktivitas bercerita pada anak

3. Menceritakan dongeng.

Mendongeng merupakan cara meneruskan warisan budaya yang berupa nilai-nilai luhur dari satu generasi ke generasi berikutnya. Dongeng dapat di gunakan untuk menyampaikan pesan-pesan kebaikan kepada anak. Oleh karena itu, seni dongeng perlu dipertahankan di dalam kehidupan anak.

4. Bercerita dengan menggunakan papan flanel.

Guru dapat membuat papan flanel dengan melapisi seluas papan dengan kain flanel yang berwarna netral, misalnya warna abu-abu. Gambar tokoh-tokoh yang mewakili perwatakan dalam ceritanya digunting polanya pada kertas yang di belakangnya dilapis dengan kertas ampelas yang paling halus untuk menempelkan pada papan flanel supaya dapat melekat.

5. Bercerita dengan menggunakan media boneka.

Pemilihan bercerita dengan menggunakan boneka akan tergantung pada usia dan pengalaman anak. Biasanya boneka terdiri dari ayah, ibu, anak laki-laki dan anak perempuan, nenek, kakek dan bisa di tambahkan anggota keluarga yang lain. Boneka yang dibuat masing-masing menunjukkan perwatakan pemegang peran tertentu.

6. Dramatisasi suatu cerita

Teknik bercerita dengan dramatisasi adalah bercerita dengan cara memainkan perwatakan tokoh-tokoh dalam suatu cerita yang disukai anak. Cerita yang ditampilkan adalah cerita yang disukai oleh anak.Pemilihan isi cerita dapat disesuaikan dengan tema yang dikembangkan, atau sikap yang ingin ditanamkan pada anak.

7. Bercerita sambil memainkan jarijari tangan.

Bercerita dengan teknik ini memungkinkan guru berkreasi dengan menggunakan jari tangannya sendiri. Guru dapat menciptakan bermacam-macam cerita dengan memainkan jari tangan, sesuai 
dengan kreativitas guru masingmasing.

Kegiatan bercerita merupakan kegiatan yang memiliki manfaat besar bagi perkembangan anak. Sebelum melaksanakan kegiatan bercerita guru terlebih dahulu harus merancang kegiatan bercerita berupa langkahlangkah yang harus ditempuh guru dalam menerapkan kegiatan bercerita di kelas. Langkah-langkah tersebut menurut Masitoh (2009:10.13) meliputi "menetapkan tujuan dan tema cerita, menetapkan bentuk bercerita yang dipilih, menetapkan bahan dan alat yang diperlukan dalam kegiatan bercerita, menetapkan rancangan langkah-langkah kegiatan bercerita dan menetapkan rancangan penilaian kegiatan bercerita". Kelima langkah atau rancangan prosedur yang harus dilalui guru dalam bercerita adalah:

a. Menetapkan tujuan dan tema cerita, yaitu menetapkan tujuan bercerita dikaitkan dengan tema yang di pilih. Tujuan mengacu kepada kemampuan yang diharapkan dapat dicapai oleh anak melalui kegiatan bercerita, yaitu memberikan informasi tentang nilai-nilai sosial, moral atau keagamaan dan menanamkan nilai-nilai sosial, moral atau keagamaan. b. Menetapkan bentuk bercerita yang dipilih, yaitu guru menetapkan bentuk cerita yang akan dipilih sesuai tema yang telah ditetapkan sebelumnya. Misalnya bercerita dengan membaca langsung dari buku cerita, menggunakan ilustrasi gambar, menggunakan papan flanel, menceritakan dongeng dan sebagainya.

c. Menetapkan bahan dan alat yang diperlukan dalam kegiatan bercerita. Bahan dan alat yang diperlukan dalam kegiatan bercerita sangat tergantung pada bentuk bercerita yang dipilih guru. Jika bentuk cerita yang dipilih bercerita dengan membaca langsung dari buku, maka guru menyiapkan buku yang sesuai dengan tema cerita serta memperlihatkan kepada anak gambar-gambar yang ada pada buku tersebut.

Menetapkan rancangan langkahlangkah kegiatan bercerita. Rancangan langkah-langkah kegiatan bercerita merupakan urutan kegiatan yang akan dilakukan oleh guru pada saat kegiatan bercerita berlangsung.

\section{SIMPULAN DAN SARAN}

SIMPULAN

Metode bercerita melalui pengetahuan Alkitab pada anak 
dapat meningkatkan kecerdasan spiritual

\section{SARAN}

Nilai-nilai spiritual agar ditanamkan kepada anak dan memberi teladan kepada anak secara intensif

\section{DAFTAR PUSTAKA}

Chatib Munif, 2014. Sekolah AnakAnak Juara, Cetakan Ketiga, Bandung: Kaifa

Creswell, John W. \& Vicki L. Plano Clark, 2007.Mixed Methods Research. (United States of America, Sage Publications.

Komaidi Didik dan Wahyu Wijayati,2011.Panduan Lengkap Penelitian Tindakan Kelas. Yogyakarta: Sabda Media.

Gardner Howard. 1993.Frames Of Mind The Theory of Multiple Intelligences. Tenth-Anniversary Edition, New York: Basic Books A Member of The Perseus Books Group
Gunarti, Winda, 2010. Metode Pengembangan Perilaku dan Kemampuan Dasar Anak Usia Dini, Jakarta: Universitas Terbuka Masitoh,dkk, 2009. Strategi Pembelajaran TK, Cetakan ketigabelas, Jakarta: Universitas Terbuka

Pratisti, Wiwien Dinar, 2008. Psikologi Anak Usia Dini, Cetakan pertama, Jakarta: Indeks

Sujiono, Yuliani Nurani, 2013. Konsep Dasar Pendidikan Anak Usia Dini, Cetakan ketujuh, Jakarta: Indeks

Suparno, Paul, 2004. Teori Intelegensi Ganda dan Aplikasinya di Sekolah, Yogyakarta: Kanisius

Departemen Pendidikan dan Kebudayaan,2015.UndangUndang RI No. 20 Tahun 2003 tentang Sistem Pendidikan Nasional, Jakarta: Direktorat Pembinaan Anak Usia Dini.

Departemen Pendidikan dan Kebudayaan, 1995.Kurikulum Pendidikan TK. Jakarta: Direktorat Pendidikan TK 